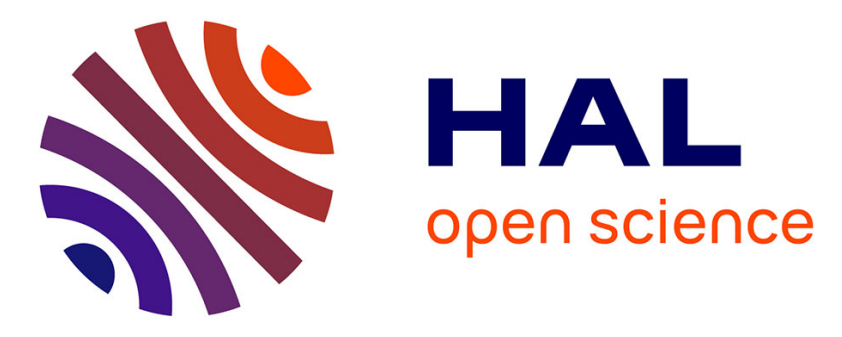

\title{
Modal analysis of an iced offshore composite wind turbine blade
}

Oumnia Lagdani, Mostapha Tarfaoui, Mourad Nachtane, Mourad Trihi, Houda Laaouidi

\section{- To cite this version:}

Oumnia Lagdani, Mostapha Tarfaoui, Mourad Nachtane, Mourad Trihi, Houda Laaouidi. Modal analysis of an iced offshore composite wind turbine blade. Wind Engineering, 2021, pp.0309524X2110116. 10.1177/0309524X211011685 . hal-03242672

\section{HAL Id: hal-03242672 \\ https://hal-ensta-bretagne.archives-ouvertes.fr/hal-03242672}

Submitted on 1 Jun 2021

HAL is a multi-disciplinary open access archive for the deposit and dissemination of scientific research documents, whether they are published or not. The documents may come from teaching and research institutions in France or abroad, or from public or private research centers.
L'archive ouverte pluridisciplinaire HAL, est destinée au dépôt et à la diffusion de documents scientifiques de niveau recherche, publiés ou non, émanant des établissements d'enseignement et de recherche français ou étrangers, des laboratoires publics ou privés. 


\title{
Modal analysis of an iced offshore composite wind turbine blade
}

\author{
Wind Engineering \\ (C) The Author(s) 2021 \\ Article reuse guidelines: \\ sagepub.com/journals-permissions \\ DOI: $10.1177 / 0309524 \times 211011685$ \\ journals.sagepub.com/home/wie
}

(SAGE

\author{
Oumnia Lagdani' ${ }^{1}$, Mostapha Tarfaoui ${ }^{2}$, Mourad Nachtane ${ }^{3}$, \\ Mourad Trihi' and Houda Laaouidi'
}

\begin{abstract}
In the far north, low temperatures and atmospheric icing are a major danger for the safe operation of wind turbines. It can cause several problems in fatigue loads, the balance of the rotor and aerodynamics. With the aim of improving the rigidity of the wind turbine blade, composite materials are currently being used. A numerical work aims to evaluate the effect of ice on composite blades and to determine the most adequate material under icing conditions. Different ice thicknesses are considered in the lower part of the blade. In this paper, modal analysis is performed to obtain the natural frequencies and corresponding mode shapes of the structure. This analysis is elaborated using the finite element method (FEM) computer program through ABAQUS software. The results have laid that the natural frequencies of the blade varied according to the material and thickness of ice and that there is no resonance phenomenon.
\end{abstract}

\section{Keywords}

Wind turbine blade, ice accretion, cold climate, hybrid composite materials, modal analysis, finite element analysis

\section{Introduction}

Renewable resources represent a large part of the world's energy demand, which is estimated to increase and satisfy up to $60 \%$ of global energy demand by 2050 (Sunden and $\mathrm{Wu}, 2015$ ).

Wind energy is currently known as a mature and reliable technology with very significant development potential. This sector has been characterized by a relatively rapid growth in recent years (Ou et al., 2016). In cold climate regions, wind turbines accumulate ice on their blades, which is a well-known and much studied topic in wind energy (Weijtjens et al., 2018).

Icing during cold seasons usually has serious consequences: measurement errors due to ice, total loss, or reduction of power generation and risks of accidents (Lamraoui et al., 2014).

The accumulation of ice on the individual wind turbine blades causes an imbalance in the rotor which represents a major risk of failure of the entire structure (Figure 1).

Due to severe weather conditions, excessive ice formation and irregular shedding are widely known to have a significant effect on turbine performance by decreasing the coefficient of lift $\left(C_{\mathrm{L}}\right)$ and significantly increasing the coefficient of drag $\left(C_{\mathrm{D}}\right)$. During icing, the surface roughness on the leading edge of the blade changes its aerodynamic profile and the resulting energy production (Figure 2; Fakorede et al., 2016; Lagdani et al., 2020).

Various materials are employed in the construction of wind turbines, thanks to their exceptional properties composite materials are the most commonly used. They are known for their very low weight and excellent

\footnotetext{
'Laboratory for Renewable Energy and Dynamic Systems, FSAC—UH2C, Casablanca, Morocco

${ }^{2}$ ENSTA Bretagne, FRE CNRS 3744, IRDL, Brest, France

${ }^{3}$ ENSAM, LEM3, Metz, France
}

\section{Corresponding authors:}

Oumnia Lagdani, Laboratory for Renewable Energy and Dynamic Systems, FSAC—UH2C, Km 8 Route d'El Jadida, 20100 Casablanca, Morocco. Email: Oumnialagdani@gmail.com

Mostapha Tarfaoui, ENSTA Bretagne, FRE CNRS 3744, IRDL, F-29200 Brest, France.

Email: mostapha.tarfaoui@ensta-bretagne.fr 


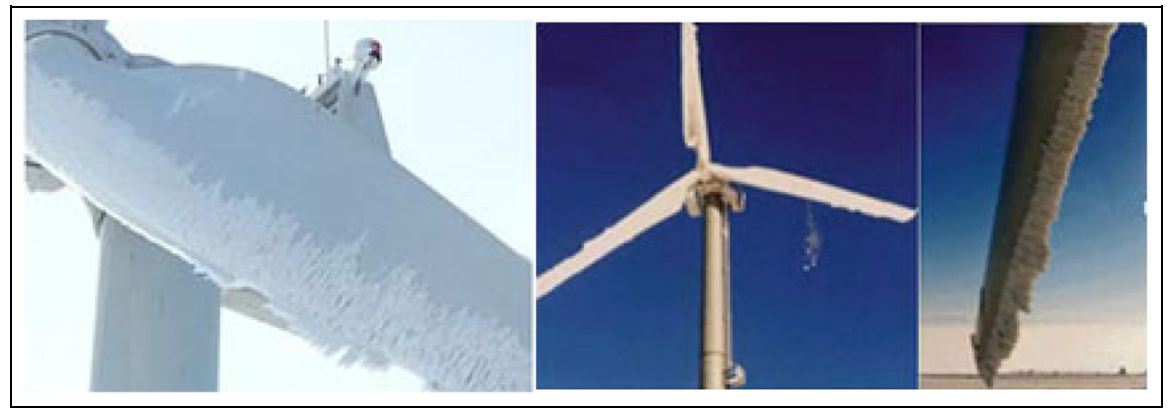

Figure I. Impact of icing on wind turbines.

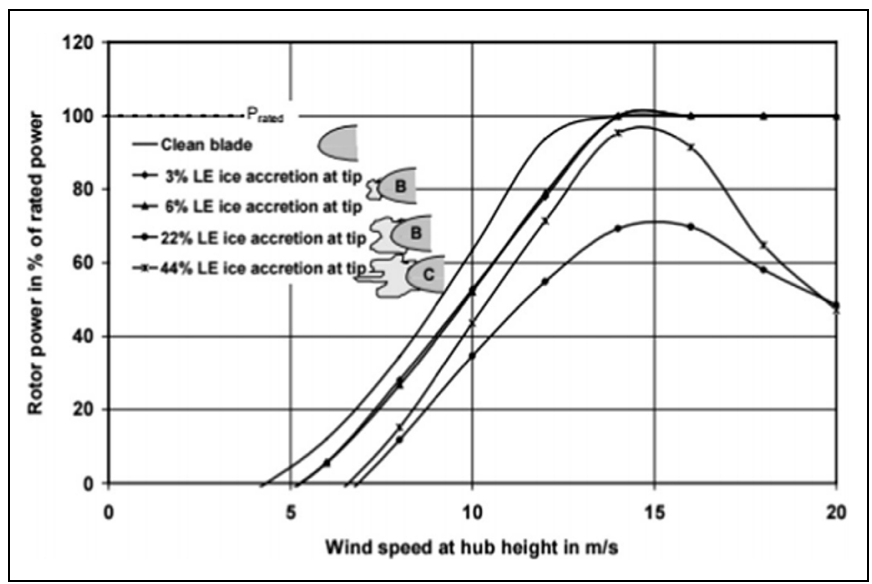

Figure 2. Power reduction curve due to ice formation.

stiffness, offering great resistance to static load and fatigue (Shokrieh and Rafiee, 2020; Supeni et al., 2012). In the wind turbine blades, Glass fiber/epoxy and wood laminates/epoxy are the most commonly used materials, but Carbon fiber is widely employed. The blades are usually composed of different sections bonded to each othersuction side, pressure side, and shear webs (Tarfaoui et al., 2013).

The conception of large blades for horizontal axis wind turbines implies many important factors in terms of strength and stability. Reduction in vibration is an essential step for a suitable structure of rotor blade. A good design for minimizing vibration consists to separate the natural frequencies of the structure from the harmonics of rotor speed. This help to prevent resonance that could seriously destroy the entire structure (Tenguria and Ahmed, 2011).

In order to control the operational behavior and security of offshore wind turbines, modal analysis is nowadays an essential method to examine the structural dynamic characteristics of kinetic systems (Gantasala et al., 2016; Zhiquan et al., 2001).

In an artificial climate chamber Shu et al. (2017) studied experimentally the icing characteristics and power of a small wind turbines. To simulate glaze ice, 3D ice accretion wind turbine model was provided by using FLUENT software. The researchers found that the iced rotor does not turn easily when the speed is below $30 \mathrm{rpm}$, and that ice increased linearly starting from the root to the tip of the blade and accumulated largely on the leading edge, reducing the rotational speed of the rotor, and subsequently causing a large loss of power. An experimental icing study was conducted by Gao et al. (2019) in a research tunnel with a wind turbine blade model to examine the degradation of its aerodynamic performance. Under defined icing conditions, ice structures are formed rapidly on the top and bottom surfaces of the model. With each increase in the angle of attack, the accumulation of ice on the intrados of the blade became less interesting than that on the extrados. It was reported in their article that the loss of the aerodynamic performance provided by ice accumulation for the same blade structure was much greater at low angles of attack. After 600 seconds of the ice accumulation experiment test, a decrease in lift by 
approximately $\sim 12 \%$ of its initial value was noted for the test case where the AOA was $5.0^{\circ}$, while the drag increased by a corresponding 4.5 times. In the refrigerated wind tunnel of the Anti-icing Materials International Laboratory (AMIL), icing simulations were tested by Hochart et al. (2007) on the 6061-T6 aluminum wind turbine blade composed by a NACA $63-415$ profile with $0.2 \mathrm{~m}$ of chord. The experimental method consisted of placing the profile at a selected angle of incidence under two icing conditions and for three different radial positions. The researchers noted during the tests in wet regime that glaze is assembled on the leading edge and along the lower surface and also accumulated by runoff water on the trailing edge for the profiles at the end and at the center of the blade structure, while dry regime tests indicate that rime is precisely accumulated on the leading edge and partially on the lower surface of the profiles situated between the middle and the tip of the blade. For the two icing events, the mass of ice increases each time we move towards the tip of the blade, the model analysis also revealed that the lift varied by around $9 \%$ over the first two thirds of the blade and augmented by $25 \%$ over the last one.

Another study carried out by Gantasala et al. (2019) they investigated the dynamic behavior of the turbine under symmetrical icing conditions at several parts of the blade and asymmetrical icing conditions over the entire blade. Their work was realized on the National Renewable Energy Laboratory (NREL) wind turbine design using a computer-aided aeroelastic engineering tool FAST. It was found that the last third of a clean blade produced close to $50 \%$ of the total power of the turbine, and that intense icing in this area resulted in a significant reduction in lift and additional drag and then led to a reduction in electrical power. The authors also indicated that an increase in blade mass caused by icing reduced its natural frequencies, and that symmetrical icing of all three blades decreased the loads acting on the turbine components, while asymmetrical icing caused loads and vibrations in the structure.

Afzal and Virk (2018) had shown that the additional mass of ice located on the leading edge of the blade has important effects on the efficiency of wind turbines. Ice formation on the surface of the wind turbine blades is not homogeneous along the entire length of the blade, it causes more loads and increase the excitation of edgewise vibrations. A material comparison was performed using the CES EDUPack; it was found that turbine blades made of carbon fiber are the most commonly adopted depending on the corrosion resistance and the capacity of great strength and hardness.

In the present work, a modal analysis is performed to evaluate the natural frequencies and mode shapes of a wind turbine blade affected by different thicknesses of ice formed on its tip. The model was evaluated numerically using ABAQUS software based on the finite element approach. Carbon fiber, Glass fiber, and Carbon/Glass hybrid composite were chosen as materials in this study to determine which one is the most resistant to the effect of ice.

The numerical results of this paper could serve as a reference for a more detailed study of the wind turbine blade's vibrations, structural dynamics, and other issues.

\section{Blade design and finite element model}

\section{Geometrical design parameters}

Rotor blades are probably the most popular and complicated wind turbine parts. This study focused on the structural design of a $48 \mathrm{~m}$ blade for a $5 \mathrm{MW}$ Horizontal Axis Wind Turbine (HAWT). The general requirements of the blade considered in the present study are indicated in Table 1 (Tarfaoui and Shah, 2013).

Table I. Technical specification of the investigated blade.

\begin{tabular}{ll}
\hline Parameters & Values \\
\hline Length of the blade $(\mathrm{m})$ & 48 \\
Maximum chord $(\mathrm{mm})$ & 3932 \\
Position twists maximum $(\mathrm{mm})$ & $\mathrm{R} 9000$ \\
Fluid speed upstream of blade $(\mathrm{m} / \mathrm{s})$ & 25 \\
Angular velocity $(\mathrm{rpm})$ & 15.7 \\
Frequency of solicitation: Fr $(\mathrm{Hz})$ & 0.26 \\
Power $(\mathrm{MW})$ & 5 \\
\hline
\end{tabular}




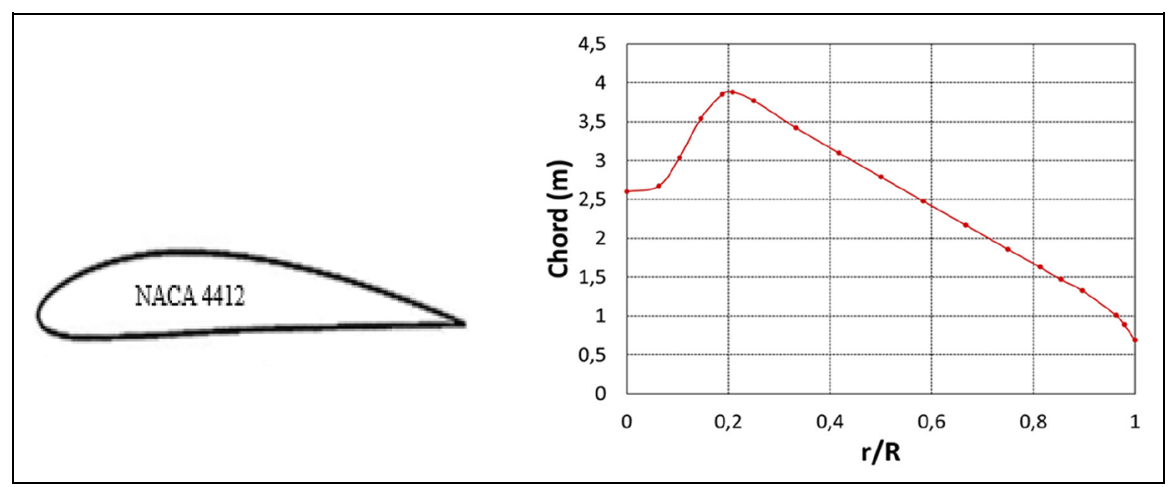

Figure 3. NACA 4412 profile, evolution of the blade chord.

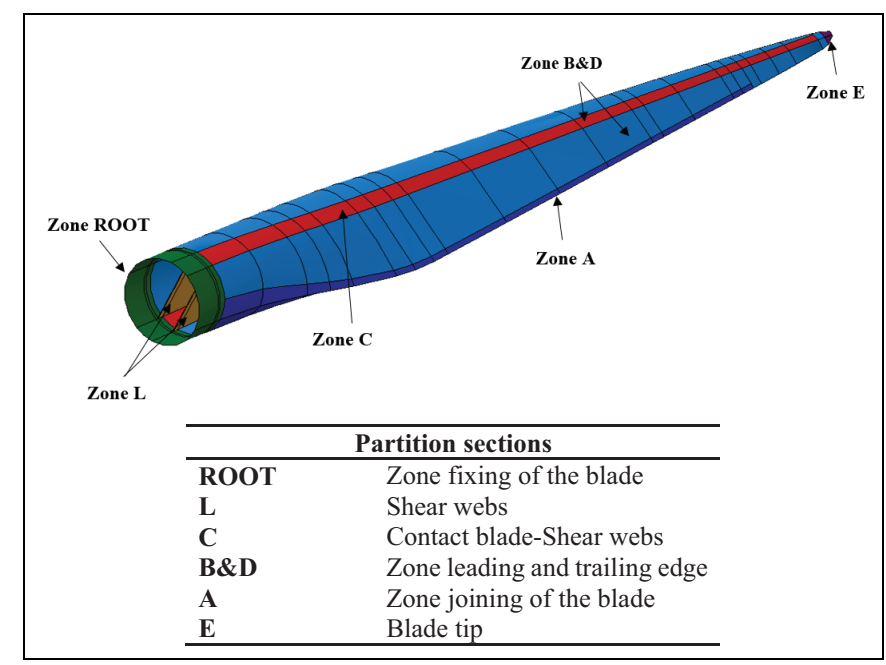

Figure 4. Different zones of a $48 \mathrm{~m}$ long rotor blade.

A Good aerodynamic performance of the blades, is the main factor that significantly influences the start-up of the work and the coefficient of performance of the wind turbines. NACA 44XX, NACA 23XXX, and NACA 63$\mathrm{XXX}$ are airfoils that are typically employed in wind turbines. Figure 3 illustrates the chosen model used in this study, which is a four-digit series of NACA 4412 type and the change in chord distribution for the selected profile of the present blade (Babadi Soultanzadeh et al., 2014). This profile has a maximum camber of $4 \%$ of chord positioned $40 \%$ measured from the leading edge, with a maximum thickness of $12 \%$ and is known for its simplicity, efficiency and has proven itself for decades.

The blades of wind turbines are typically constructed in multiple parts, the inner and outer sections of the geometry are adhesively joined together and connected by means of two vertical shear-webs (Mishnaevsky et al., 2017). In what follows, the wind turbine blade structure has been divided into six different zones, their positions are indicated in Figure 4. The purpose of these sections is to reproduce more combinations (thickness and orientation of successive layers) of the materials employed depending on the need (Tarfaoui et al., 2017).

\section{Blade manufacture}

Wind turbine blades are fabricated by identical techniques to those employed for composite ship hulls and aircraft structures; such as, hand lay-up, pre-preg manufacturing technology, vacuum Infusion, and resin transfer molding (Holmes et al., 2007).

For longer blades, the most used construction method is the Resin Transfer Molding technology. It consists to make the two aeroshells in external molds. Webs are then placed in between the aeroshells and the parts are then bonded together (Figure 5; Mishnaevsky et al., 2017). 


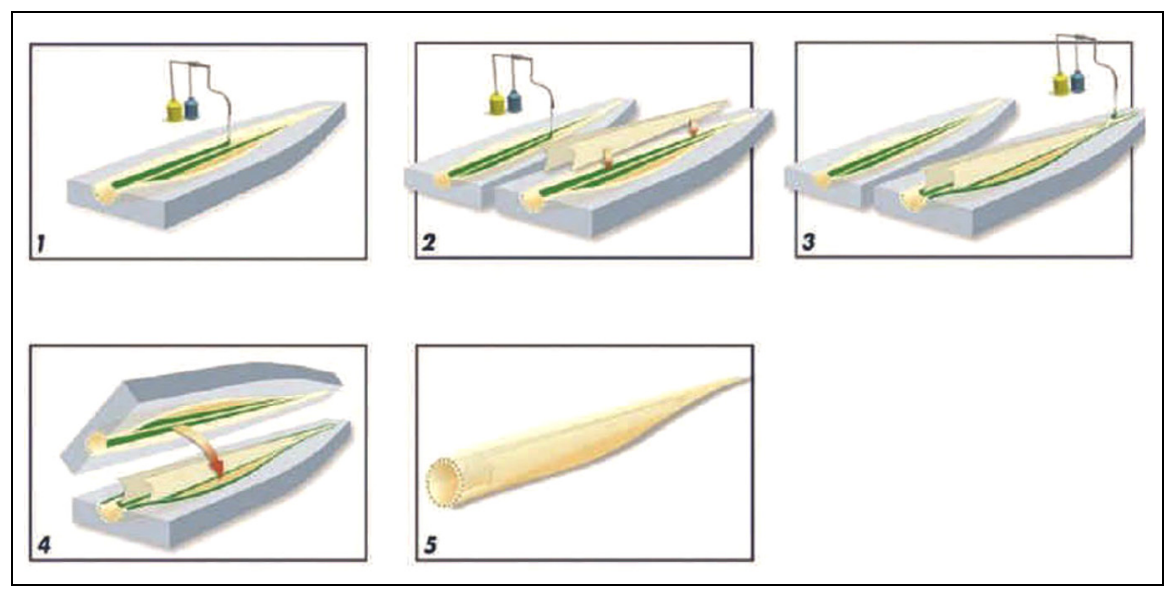

Figure 5. Different steps for manufacturing a composite blade (Rahman, 2014).

Table 2. Composite properties for blade modeling (Gemi, 20I8).

\begin{tabular}{lll}
\hline Materials, properties & Carbon-epoxy & Glass-epoxy \\
\hline$\rho\left(\mathrm{kg} / \mathrm{m}^{3}\right)$ & 1442 & 1649 \\
$E_{1}(\mathrm{GPa})$ & 18.850 & 25.750 \\
$E_{2}(\mathrm{GPa})$ & 3.880 & 6.208 \\
$\mathrm{Nu}_{12}$ & 0.346 & 0.330 \\
$G_{12}(\mathrm{GPa})=G_{13}(\mathrm{GPa})$ & 1.430 & 2.304 \\
$G_{23}(\mathrm{GPa})$ & 1.320 & 2.160 \\
\hline
\end{tabular}

The process starts with the application of a gel coat that can be brushed or sprayed on the upper and lower parts of a rigid mold which is then closed and clamped to combine the two parts. Once it is fully closed, the resin pump simultaneously pumps the catalyst and resin to the mixing head, where they are mixed together, and inject them into the mold cavity a single component material. Resin is then introduced between the molds from a central point. It is normal that some resin will flow around their extremities which will announce that the complete saturation is achieved, the resin inlet is closed. When the resin has completely solidified, the mold is finally removed (Danisman et al., 2007).

\section{Wind turbine blade materials}

Composite materials have appeared as a major class of modern elements and are currently considered as alternatives to traditional metals/materials employed in a variety of applications. The characteristics of composites are their high rigidity and excellent resistance which make them very advantageous as materials (Kar, 2017).

The wind turbine blades are designed toward stiffness and fatigue. Therefore, the materials needed for the blades should be very high performance materials. For these reasons, composite materials are being the preferred choice (Brøndsted et al., 2005).

The majority of the blades are fabricated from fiberglass reinforced with polyester or epoxy resin. Longer blades require the application of another materials, generally Carbon-based composites (Davies et al., 2013; Rivkin and Silk, 2012). Two composite materials were chosen, the material properties employed in this study are summarized in Table 2.

However, there are many combinations of fiber directions that can be applied, but the $0 / \pm 45$ ply layup is the most suitable from a manufacturing point of view (Cox and Echtermeyer, 2012). The distribution of the $48 \mathrm{~m}$ long wind turbine blade adopted in this work and some examples of the distribution of materials in each section are respectively shown in Figures 6 and 7.

Table 3, regroups the mechanical properties of the additional isotropic materials used in this design, including foam core material (SKINFOAM). The different components of the blade have to be well assembled. For this, it is essential to incorporate an adhesive layer (Figure 8). Its properties are mentioned in Table 3 (Tarfaoui et al., 2020). 


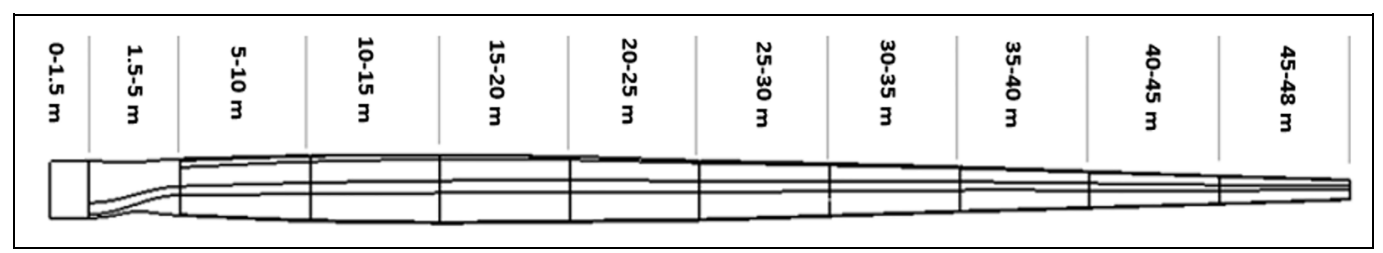

Figure 6. Blade partitions in terms of radius from the root.
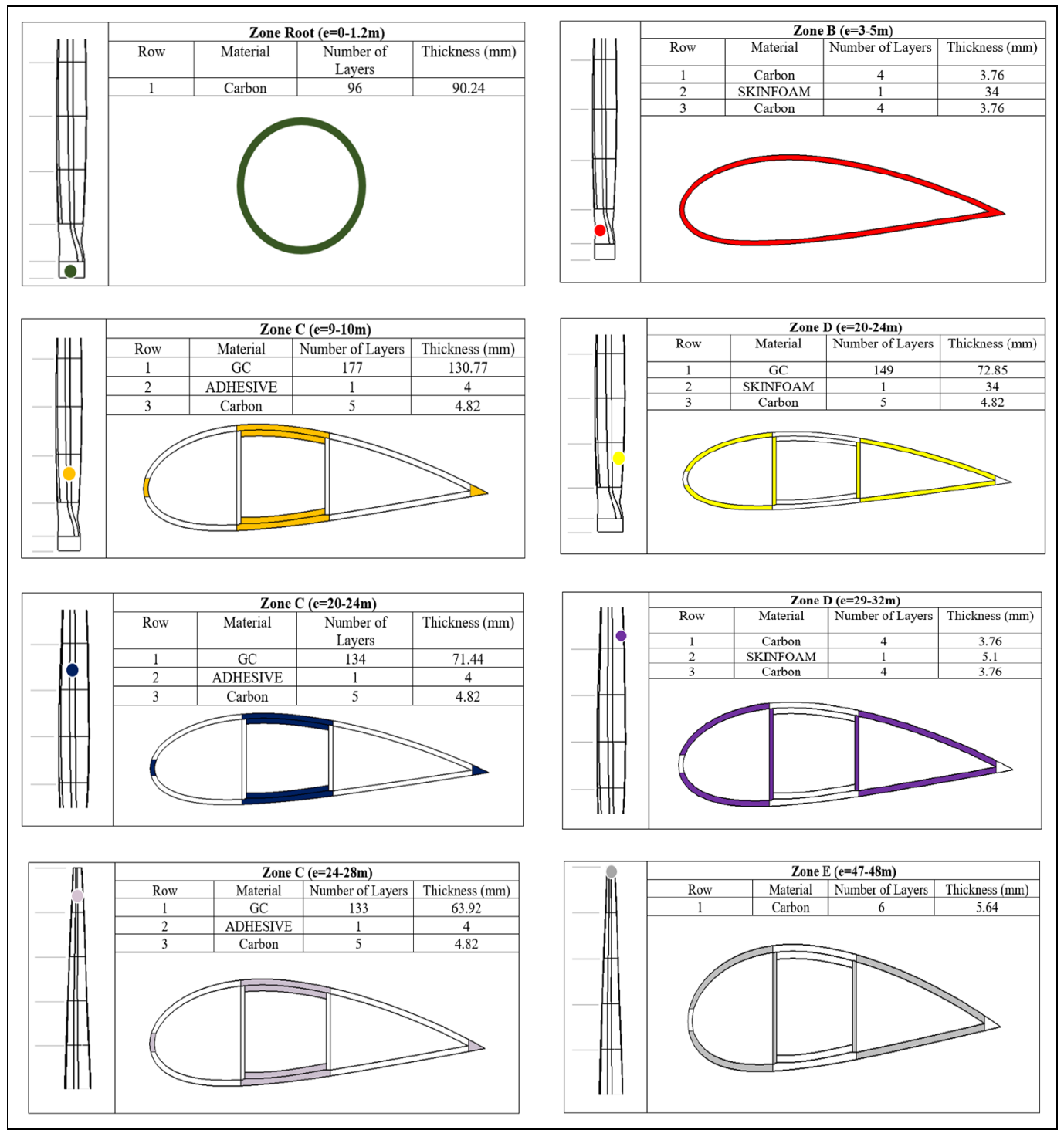

Figure 7. Example of the distribution of materials in the section of wind turbine blade.

\section{Mesh study}

The finite element method (FEM) is based on dividing the blade geometry into small domains according to the type of mesh. The finer the mesh size, the higher and more accurate the FEM solution will be (Elalaoui, 2019).

The present model uses a mesh size of $200 \mathrm{~mm}$ of S4R type shell elements for the whole geometry except the tip of the blade, which is triangular elements of type S3R of small size in order to eradicate mesh defects, Figure 9 illustrates the blade mesh size. The shell elements give the identical degree of accuracy as solid elements with lower 
Table 3. Mechanical properties of the skinfoam and the adhesive (Tarfaoui et al., 2020).

\begin{tabular}{llllll}
\hline Materials & $\rho\left(\mathrm{kg} / \mathrm{m}^{3}\right)$ & $E_{11}(\mathrm{MPa})$ & $E_{12}(\mathrm{MPa})$ & $G_{12}=G_{13}=G_{23}(\mathrm{MPa})$ & $v_{12}$ \\
\hline Skinfoam & 200 & 256 & 256 & 22 & 0.3 \\
Adhesive & 1200 & 3000 & 3000 & 1150 & 0.3 \\
\hline
\end{tabular}

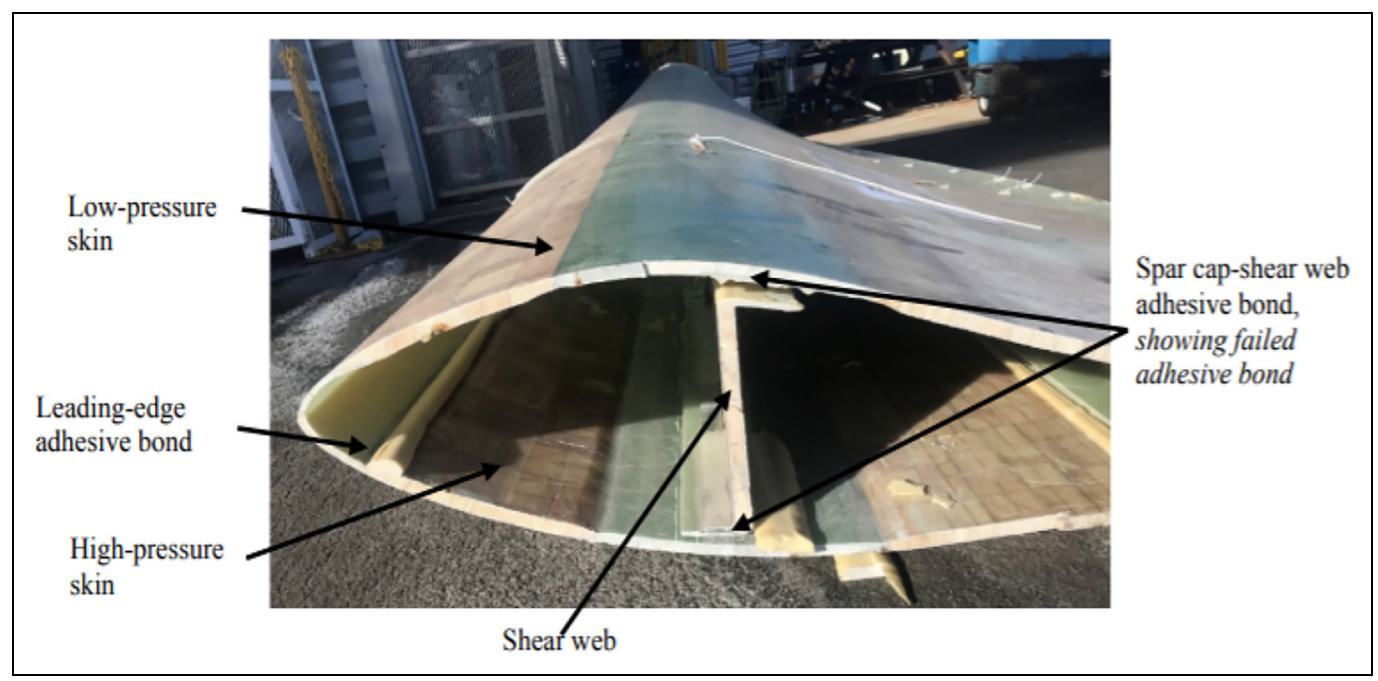

Figure 8. Adhesive for bonding wind turbine blades (Murray et al., 2019).

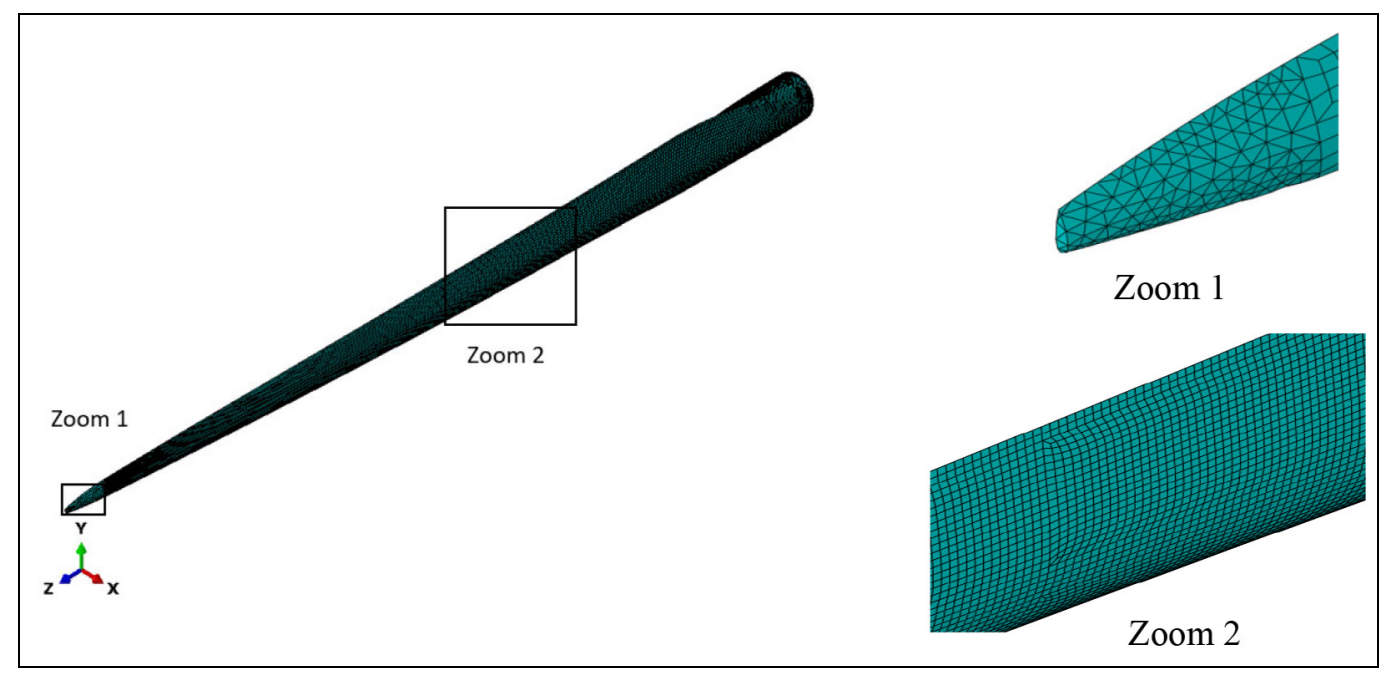

Figure 9. Mesh of model.

calculation costs. It is for these purposes that it is preferable to utilize it rather than the solid elements (Boudounit et al., 2020).

However, for the rest of this work, the model analyzed in this article is a $48 \mathrm{~m}$ long industrial wind turbine blade. The objective is to study the behavior of the blade following the icing phenomenon using each time Carbon fibers and Glass fibers, and also to see the effect of the Carbon/Glass hybrid composite materials.

In what follows we note "Blade 1" for a Carbon blade with Hybrid packets of Carbon-Glass (CG) layers localized at the section C shown previously in Figure 4, and "Blade 2" for a Glass blade with packets of Glass-Carbon (GC) layers at the $\mathrm{C}$ zone. 


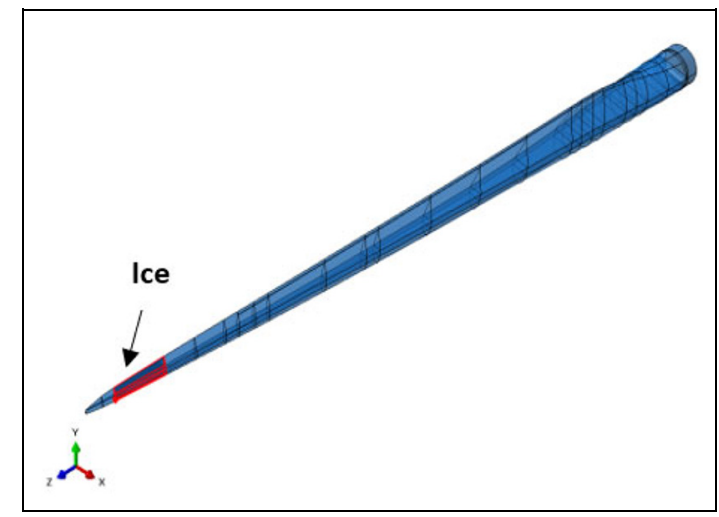

Figure 10. Iced blade.

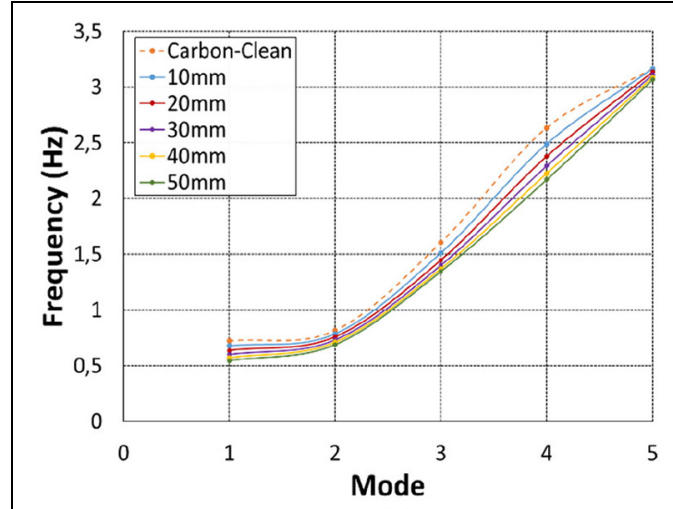

(a)

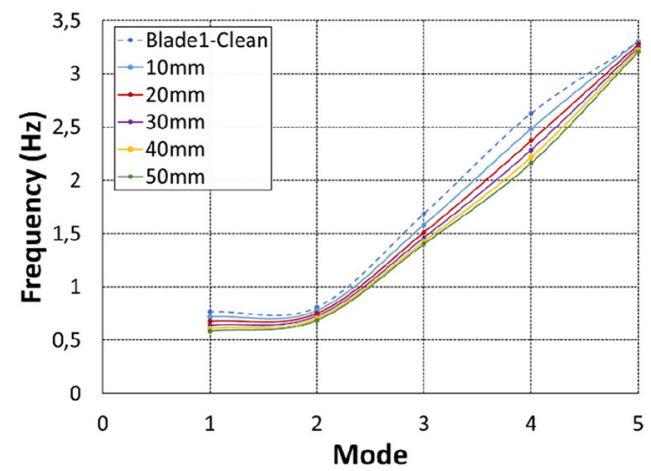

(c)

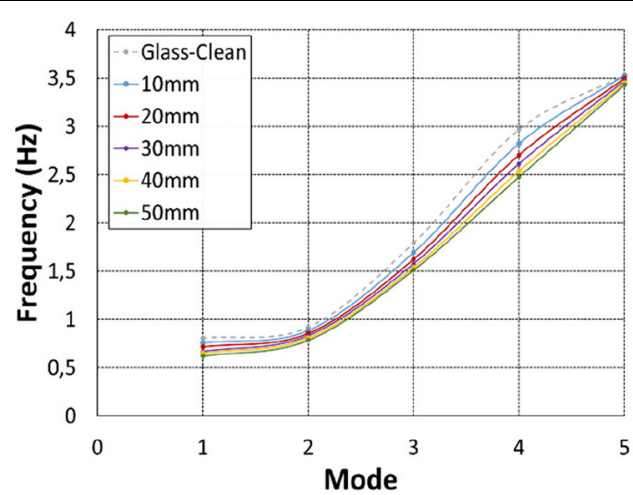

(b)

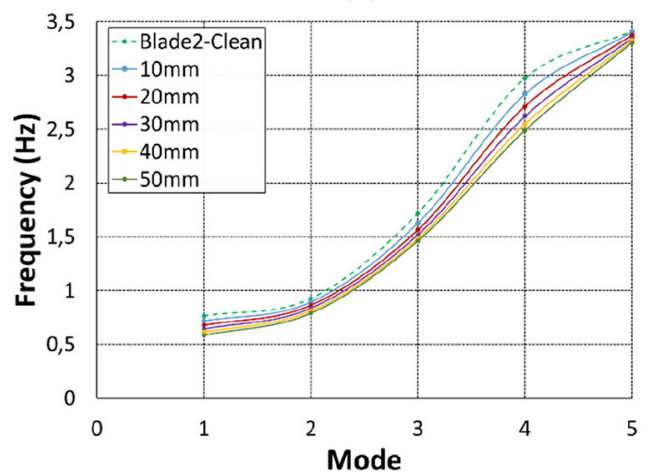

(d)

Figure I I. Comparison of natural frequency of clean and iced blade with different thick of ice for five modes: (a) Carbon, (b) Glass, (c) Blade I, and (d) Blade 2.

It is considered that ice is on the side of the tip of the blade with a length of $3.213 \mathrm{~m}$ and a distance from the rotor equal to $43.031 \mathrm{~m}$ (Figure 10).

\section{Modal analysis}

Modal testing analysis is the most common approach for determining the dynamic properties of a mechanical system. The blades have recently received much attention they are becoming taller and more flexible than before 


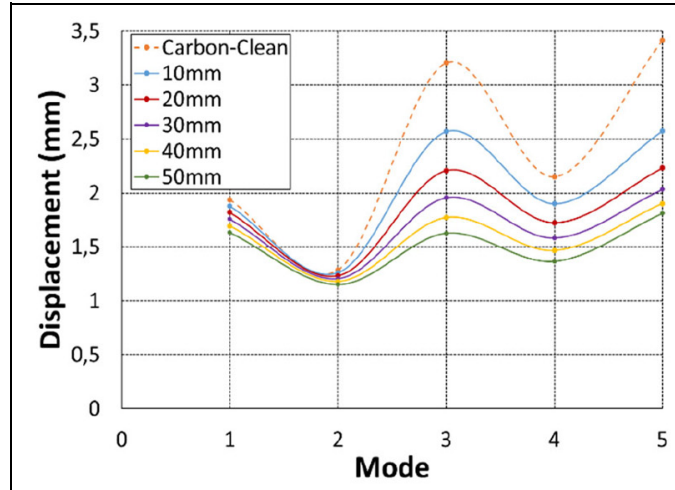

(a)

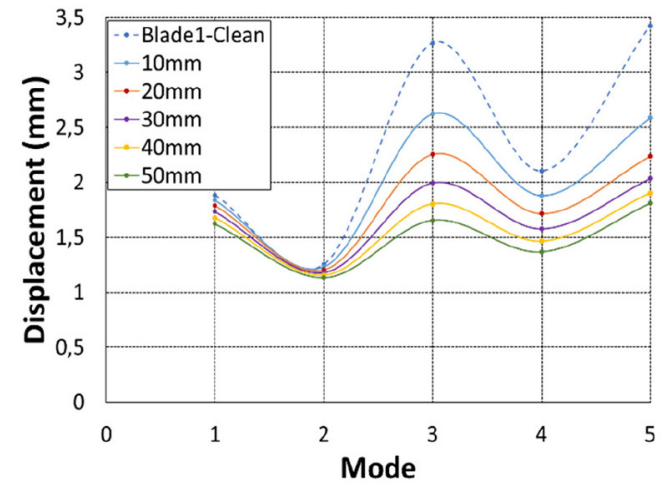

(c)

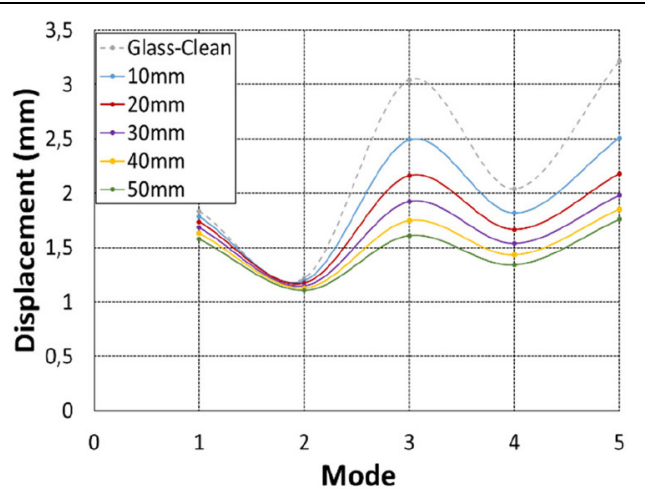

(b)

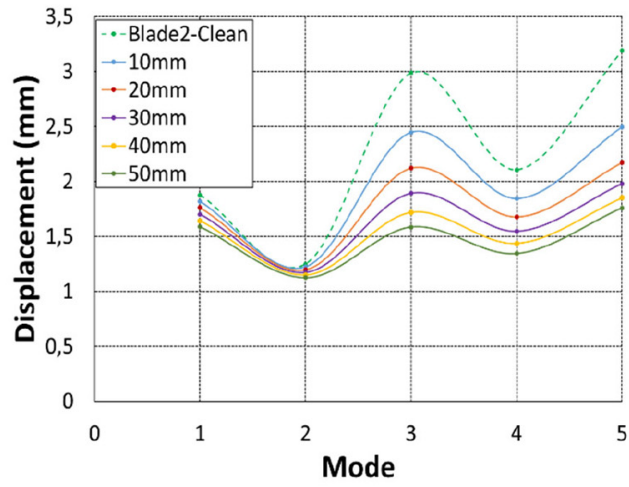

(d)

Figure I 2. Comparison of displacement of clean and iced blade with different thick of ice for five modes: (a) Carbon, (b) Glass, (c) Blade I, and (d) Blade 2.

causing problems of structural instability. It is then essential to perform vibration characteristics in the design and development process of the structure (Li et al., 2015; Sellami et al., 2016).

The modal will indicate in which frequency range the blade will be more sensitive to vibrations.

Modal analysis of a horizontal axis wind turbine blade is performed to evaluate the natural frequencies and modal shapes of a composite blade at different modes.

In our study, the modal analysis is elaborated by the finite element method using ABAQUS software by fixing the root of the blade and leaving the tip free to vibrate. In order to provide a better analysis, the point at the blade tip is chosen as reference.

\section{Effect of ice layer thickness}

The effect of ice on the wind turbine blades has been treated and a number of numerical tests evaluated the behavior of different thicknesses of ice (10, 20,30, 40, and $50 \mathrm{~mm})$ accumulated on the tip of a composite blade.

The modal analysis in ABAQUS resulted in giving the values of the 5 first natural frequencies of the wind turbine blade. According to Figure 11, a shift in frequency due to the addition of ice on the blade was observed and, it is also clear that increasing thickness decreases the natural frequency.

Composite blade made of Carbon has lower natural frequencies than Glass, Blade 1 and Blade 2. A larger gap between the natural frequencies of the clean and iced rotor was detected in the fourth mode for the different blade materials.

For a Carbon blade, the fourth mode is most impacted by the presence of ice. In comparison with the clean blade, a reduction of $5.47 \%$ is observed for a thickness of ice equal to $10 \mathrm{~mm}, 9.67 \%, 12.93 \%$, and $15.51 \%$ for the 20,30 , and $40 \mathrm{~mm}$ while a reduction of $17.59 \%$ was detected for the $50 \mathrm{~mm}$ of ice.

From Figure 12, the behavior of the graph for all composite materials is same. It can be seen that the formation of a $50 \mathrm{~mm}$ thick layer of ice has the smallest displacement, this could be explained by the high weight of the ice added at the tip of the blade. 


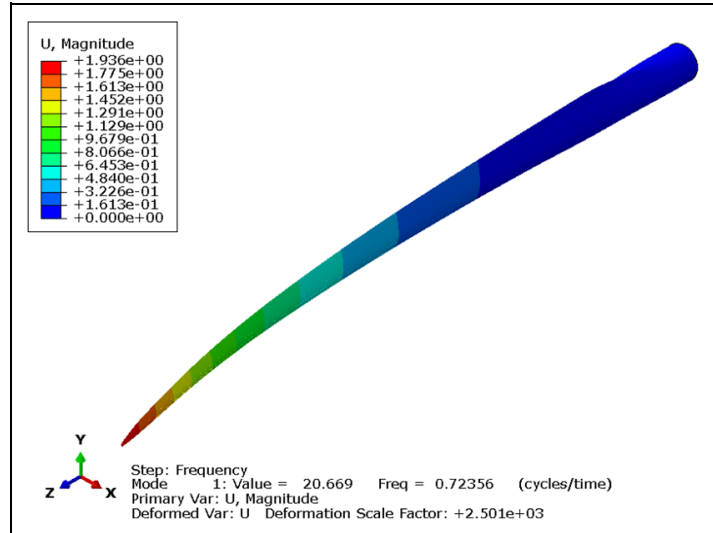

(a)

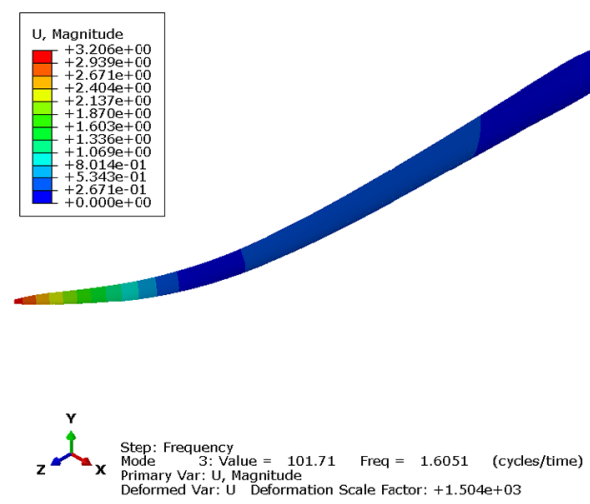

(c)

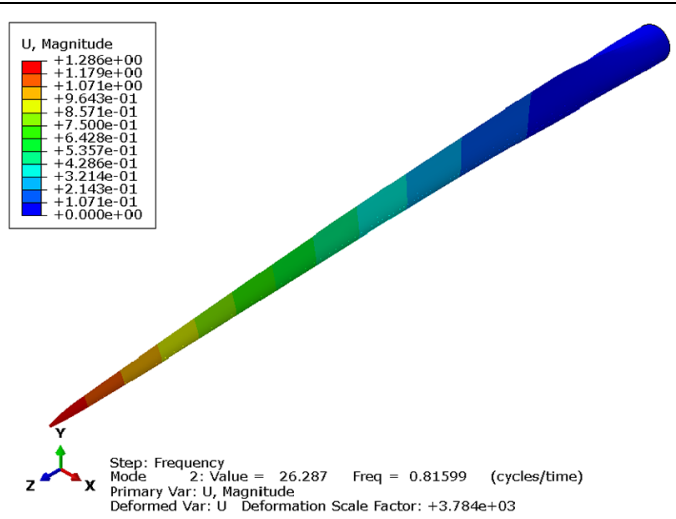

(b)

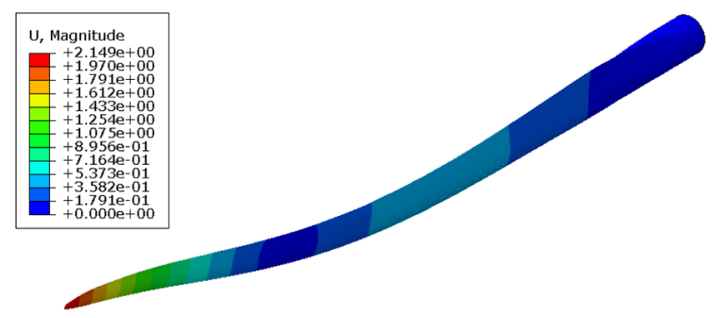

(d)
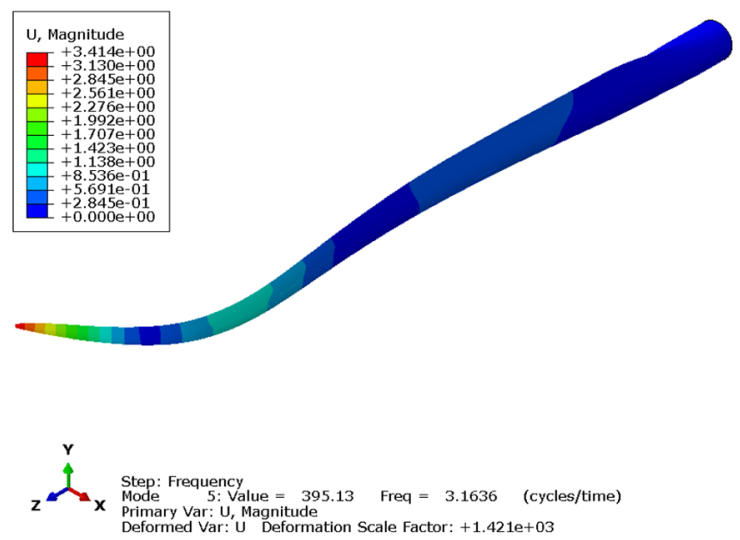

(e)

Figure 13. The five modes shapes of the clean Carbon blade: (a) mode I, (b) mode 2, (c) mode 3, (d) mode 4, and (e) mode 5.

\section{Material effect}

Material is a crucial factor in the durability of wind turbine blades. The natural frequencies and maximum displacement for the five modes of vibrations, obtained from the modal analysis of the clean and iced blade with constant ice thickness $(50 \mathrm{~mm})$, for different materials are presented in Tables 4 and 5, mode shapes and maximum displacements are listed in Figures 13 and 14.

Figure 15 represent a comparison of the blade frequency variation according to the mode for different materials for a clean and an iced blade. It is remarked that the natural frequency varies and increases from mode 1 to 5. 
Table 4. Natural frequency of clean blade, for different materials.

\begin{tabular}{lllll}
\hline & Carbon & Glass & Blade I & Blade 2 \\
\hline Natural frequency $(\mathrm{Hz})$ & & & & 0.766 \\
Mode I & 0.723 & 0.804 & 0.807 & 0.764 \\
Mode 2 & 0.815 & 0.915 & 1.685 & 0.925 \\
Mode 3 & 1.605 & 1.789 & 2.627 & 1.718 \\
Mode 4 & 2.633 & 2.967 & 3.301 & 2.974 \\
Mode 5 & 3.163 & 3.528 & & 3.410 \\
Displacement $(\mathrm{mm})$ & & & 1.885 & 1.876 \\
Mode I & 1.936 & 1.836 & 1.256 & 1.248 \\
Mode 2 & 1.286 & 1.220 & 3.267 & 2.987 \\
Mode 3 & 3.206 & 3.042 & 2.105 & 3.106 \\
Mode 4 & 2.149 & 2.040 & 3.424 & 3.189 \\
Mode 5 & 3.414 & 3.218 & \\
\hline
\end{tabular}

Table 5. Natural frequency of iced blade $(50 \mathrm{~mm})$, for different materials.

\begin{tabular}{lllll}
\hline & Carbon & Glass & Blade I & Blade 2 \\
\hline Natural frequency $(\mathrm{Hz})$ & & & & 0.582 \\
Mode I & 0.544 & 0.620 & 0.684 & 0.584 \\
Mode 2 & 0.687 & 0.783 & 1.401 & 0.787 \\
Mode 3 & 1.344 & 1.511 & 2.161 & 1.460 \\
Mode 4 & 2.170 & 2.476 & 3.206 & 3.487 \\
Mode 5 & 3.066 & 3.428 & 1.622 & 1.587 \\
Displacement $(\mathrm{mm})$ & & & 1.133 & 1.124 \\
Mode I & 1.634 & 1.578 & 1.657 & 1.585 \\
Mode 2 & 1.153 & 1.106 & 1.368 & 1.344 \\
Mode 3 & 1.628 & 1.612 & 1.811 & \\
Mode 4 & 1.367 & 1.342 & 1.761 & \\
Mode 5 & 1.811 & & & \\
\hline
\end{tabular}

The natural frequencies of Carbon blade and Blade 1 and also Glass and Blade 2 are nearly identical to each other for the second and fourth mode of vibration and natural frequencies of Carbon material values are lowest for same modes.

For clean blade, natural frequency of Carbon for mode 1 is $0.723 \mathrm{~Hz}$ and for mode 5 is $3.163 \mathrm{~Hz}$; and for the iced blade, it is equal to $0.544 \mathrm{~Hz}$ in mode 1 and $3.066 \mathrm{~Hz}$ in mode 5. It is then clear that the blade is influenced by the accumulation of $50 \mathrm{~mm}$ of ice at the blade tip.

Figure 16 illustrates the difference in mass of the wind turbine blade as a function of the materials employed in the simulation. It is easily seen that the mass of the blade increases when ice is added to the structure. After comparing the results of the five different thicknesses of ice, it is decided that Carbon is less heavy than others materials. For $50 \mathrm{~mm}$ of ice, the mass of Carbon has the lowest value which is $10.1 \mathrm{~T}$ compared to Glass, Blade 1 and Blade 2 which is respectively $11.2,10.41$, and $10.88 \mathrm{~T}$. We conclude that Carbon is then the right choice for a wind turbine blade.

\section{Resonance}

Reducing vibration is a very effective way to successfully perform the wind turbine blade design. The phenomenon of resonance happens in a structure when an excitation or forcing frequency is equal or close to one of the natural frequencies of the system (Tartibu et al., 2012).

Based on standard GL Wind2003 (Germanischer Lloyd Wind Energy GMBH, 2005), the equation (1) represents a condition that must be satisfied in order to avoid the resonance phenomenon that can lead to structural failure (Tarfaoui et al., 2015): 


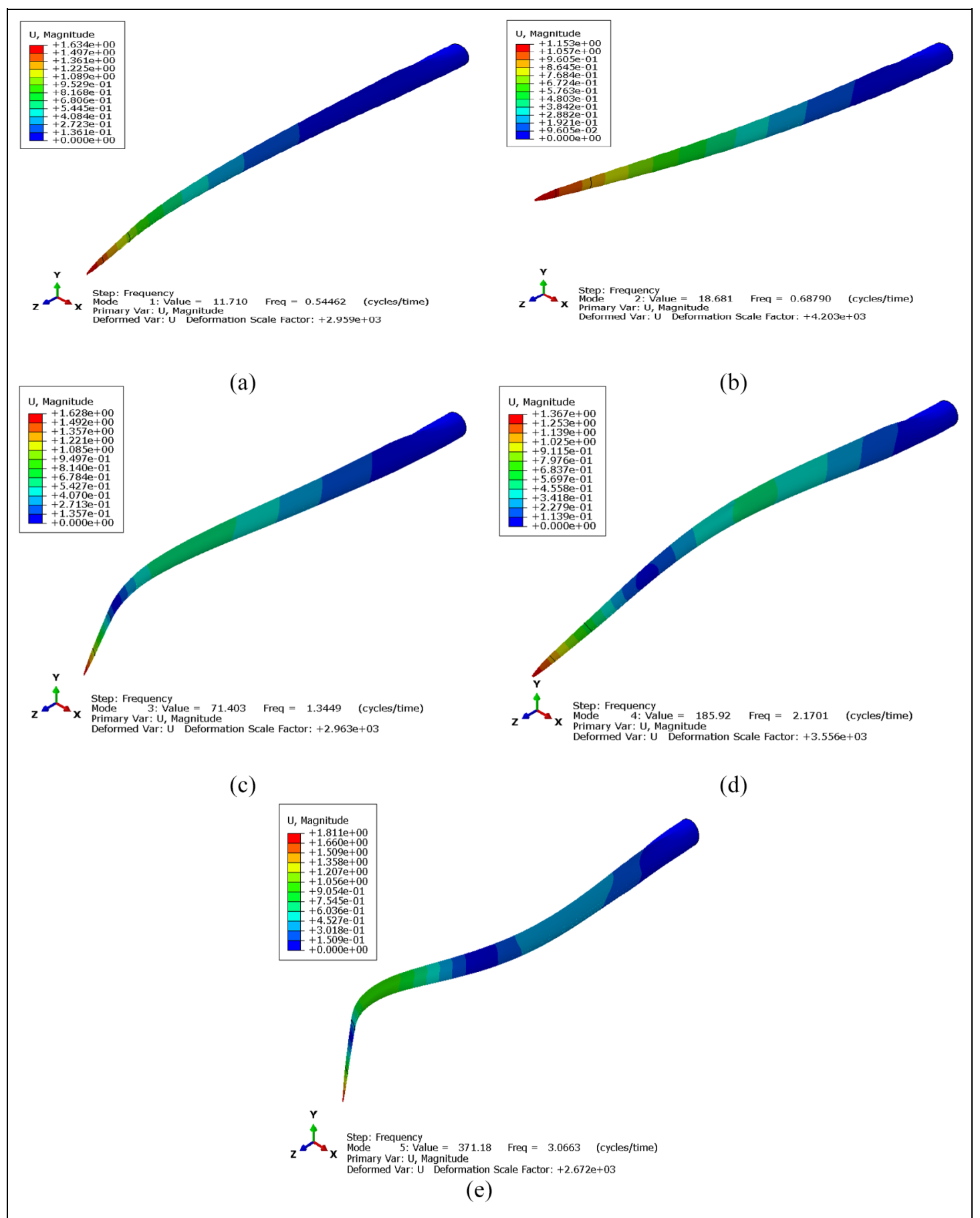

Figure 14. The five modes shapes of the iced Carbon blade $(50 \mathrm{~mm})$ : (a) mode I, (b) mode 2, (c) mode 3, (d) mode 4, and (e) mode 5.

$$
\frac{F_{r}}{F_{0, n}} \leqslant 0.95
$$

Where:

$F_{r}$ is the loading frequency, which has a value of $0.26 \mathrm{~Hz}$.

$F_{0, n}$ is the $n$-th natural frequency of the structure.

From the results grouped in Tables 6 and 7, it is clear that the ratio is always less than 0.95. It can therefore be deduced that the resonance phenomenon does not occur for the five different modes of the iced and clean blade. 


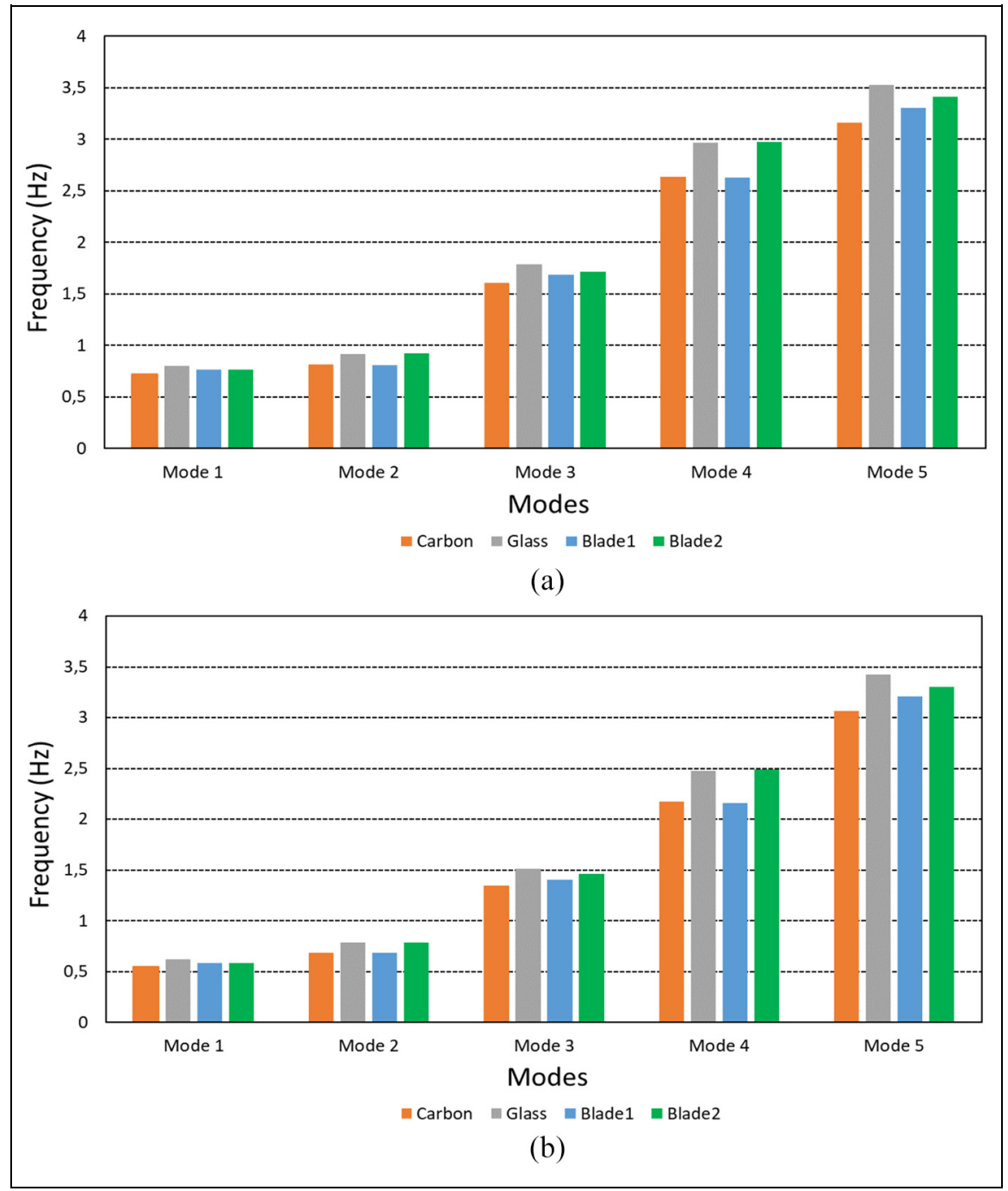

Figure 15. Comparison of the blade frequency variation according to the mode for different materials: (a) clean blade and (b) iced blade $(50 \mathrm{~mm})$.

Table 6. Results of the resonance condition of the clean blade, which is made of different materials.

\begin{tabular}{llllll}
\hline & $\frac{F_{r}}{F_{0,1}}$ & $\frac{F_{r}}{F_{0,2}}$ & $\frac{F_{r}}{F_{0,3}}$ & $\frac{F_{r}}{F_{0,4}}$ & $\frac{F_{r}}{F_{0,5}}$ \\
\hline Carbon & 0.359 & 0.318 & 0.161 & 0.098 & 0.082 \\
Glass & 0.323 & 0.283 & 0.145 & 0.087 & 0.073 \\
Blade 1 & 0.339 & 0.322 & 0.154 & 0.098 & 0.078 \\
Blade 2 & 0.340 & 0.280 & $0.15 \mathrm{I}$ & 0.0874 & 0.076 \\
\hline
\end{tabular}

\section{Conclusion}

Climates exposed to freezing temperatures generally experience icing phenomena. As winds in these regions are generally favorable for the implementation of wind turbines, the blade surfaces are necessarily exposed to icing.

Rotor blade is a critical essential part of a wind turbine structure, which is now increasingly constructed of composite materials. The dynamic performance of the blade has been verified by modal analysis. Five natural frequencies and five mode shapes are extracted for iced and un-iced composite wind turbine blades made of different materials. The simulation results are compared with each other and showed that the natural frequencies of the 


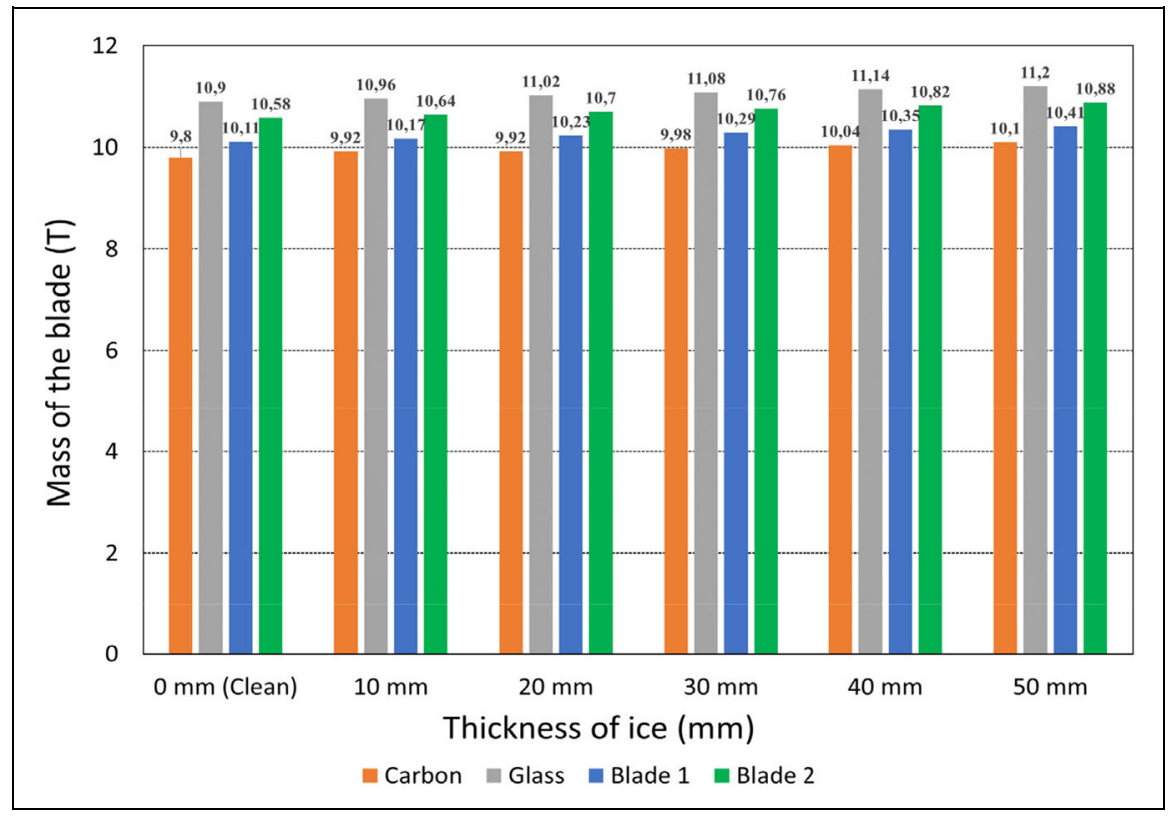

Figure 16. Mass of the blade model.

Table 7. Results of the resonance condition of composite blade for different ice thicknesses.

\begin{tabular}{|c|c|c|c|c|c|c|c|c|c|c|}
\hline$(\mathrm{mm})$ & $\frac{F_{r}}{F_{0,1}}$ & $\frac{F_{r}}{F_{0,2}}$ & $\frac{F_{r}}{F_{0,3}}$ & $\frac{F_{r}}{F_{0,4}}$ & $\frac{F_{r}}{F_{0,5}}$ & $\frac{F_{r}}{F_{0,1}}$ & $\frac{F_{r}}{F_{0,2}}$ & $\frac{F_{r}}{F_{0,3}}$ & $\frac{F_{r}}{F_{0,4}}$ & $\frac{F_{r}}{F_{0,5}}$ \\
\hline & Carbon & & & & & Glass & & & & \\
\hline 10 & 0.383 & 0.330 & 0.172 & 0.104 & 0.082 & 0.342 & 0.293 & 0.153 & 0.092 & 0.073 \\
\hline 20 & 0.408 & 0.342 & 0.179 & 0.109 & 0.082 & 0.362 & 0.303 & 0.160 & 0.096 & 0.074 \\
\hline 30 & 0.431 & 0.354 & 0.185 & 0.113 & 0.083 & 0.389 & 0.312 & 0.165 & 0.099 & 0.074 \\
\hline 40 & 0.455 & 0.366 & 0.189 & 0.116 & 0.084 & 0.400 & 0.322 & 0.168 & 0.102 & 0.075 \\
\hline \multirow[t]{2}{*}{50} & 0.477 & 0.377 & 0.193 & 0.119 & 0.084 & 0.419 & 0.331 & 0.172 & 0.104 & 0.075 \\
\hline & Blade I & & & & & Blade 2 & & & & \\
\hline 10 & 0.360 & 0.333 & 0.164 & 0.104 & 0.078 & 0.361 & 0.290 & 0.159 & 0.091 & 0.076 \\
\hline 20 & 0.382 & 0.345 & 0.171 & 0.109 & 0.079 & 0.383 & 0.300 & 0.166 & 0.095 & 0.077 \\
\hline 30 & 0.404 & 0.357 & 0.177 & 0.113 & 0.080 & 0.404 & 0.310 & 0.171 & 0.099 & 0.077 \\
\hline 40 & 0.425 & 0.368 & 0.182 & 0.117 & 0.080 & 0.425 & 0.320 & 0.174 & 0.102 & 0.078 \\
\hline 50 & 0.446 & 0.379 & 0.185 & 0.120 & 0.081 & 0.4450 & 0.329 & 0.178 & 0.104 & 0.078 \\
\hline
\end{tabular}

blade change differently depending on the thickness of ice, and that Carbon blade has the lowest natural frequencies than Glass, Blade 1 and Blade 2 composite blade. Modal analysis confirms that the blade moves in a stable way and that that is unaffected by resonance phenomena for all materials.

\section{Declaration of conflicting interests}

The author(s) declared no potential conflicts of interest with respect to the research, authorship, and/or publication of this article.

\section{Funding}

The author(s) received no financial support for the research, authorship, and/or publication of this article.

\section{ORCID iD}

Oumnia Lagdani (iD https://orcid.org/0000-0002-5182-9340 


\section{References}

Afzal F and Virk MS (2018) Review of icing effects on wind turbine in cold regions. In: E3S Web of Conferences, vol. 72, p.01007. Tokyo, Japan, 1-3 June. EDP Sciences. https://doi.org/10.1051/e3sconf/20187201007

Babadi Soultanzadeh M, Mehmandoost Esfahani B and Toghraee Semiromi D (2014) Empirical study of combined airfoil of wind turbine for using in small turbines. European Online Journal of Natural and Social Sciences 3(3): 227.

Boudounit H, Tarfaoui M, Saifaoui D, et al. (2020) Structural analysis of offshore wind turbine blades using finite element method. Wind Engineering 44: 168-180.

Brøndsted P, Lilholt H and Lystrup A (2005) Composite materials for wind power turbine blades. Annual Review of Materials Research 35(1): 505-538.

Cox K and Echtermeyer A (2012) Structural design and analysis of a 10 MW wind turbine blade. Energy Procedia 24: 194-201.

Danisman M, Tuncol G, Kaynar A, et al. (2007) Monitoring of resin flow in the resin transfer molding (RTM) process using point-voltage sensors. Composites Science and Technology 67(3-4): 367-379.

Davies P, Germain G, Gaurier B, et al. (2013) Evaluation of the durability of composite tidal turbine blades. Philosophical Transactions of the Royal Society A: Mathematical, Physical and Engineering Sciences 371(1985): 20120187-20120187.

Elalaoui R (2019) Investigation and analysis of static and dynamic behaviour of a new natural composite material of a wind turbine blade using the finite element method. International Journal of Renewable Energy Research 9(1): 363-373.

Fakorede O, Feger Z, Ibrahim H, et al. (2016) Ice protection systems for wind turbines in cold climate: Characteristics, comparisons and analysis. Renewable and Sustainable Energy Reviews 65: 662-675.

Gantasala S, Luneno J-C and Aidanpää J-O (2016) Influence of icing on the modal behavior of wind turbine blades. Energies 9(11): 862.

Gantasala S, Tabatabaei N, Cervantes M, et al. (2019) Numerical investigation of the aeroelastic behavior of a wind turbine with iced blades. Energies 12(12): 2422.

Gao L, Liu Y, Zhou W, et al. (2019) An experimental study on the aerodynamic performance degradation of a wind turbine blade model induced by ice accretion process. Renewable Energy 133: 663-675.

Gemi L (2018) Investigation of the effect of stacking sequence on low velocity impact response and damage formation in hybrid composite pipes under internal pressure. A comparative study. Composites Part B: Engineering 153: 217-232.

Germanischer Lloyd Wind Energy GMBH (2005) Guideline for the Certification of Wind Turbines.

Hochart C, Fortin G, Perron J, et al. (2007) Icing simulation of wind turbine blades. In: 45th AIAA aerospace sciences meeting and exhibit. Reno, Nevada.

Holmes JW, Sørensen BF and Brøndsted P (2007) Reliability of wind turbine blades: An overview of materials testing. In: Proceedings of the wind power, Shanghai, 1-3 November 2007.

Kar KK and Ahankari SS (2017) Functionally graded composites: processing and applications. In: Composite Materials pp. 119-168. Springer, Berlin, Heidelberg.

Lagdani O, Tarfaoui M, Nachtane M, et al. (2020) A numerical investigation of the effects of ice accretion on the aerodynamic and structural behavior of offshore wind turbine blade. Wind Engineering. Epub ahead of print 29 December 2020. DOI: 10.1177/0309524X20983220.

Lamraoui F, Fortin G, Benoit R, et al. (2014) Atmospheric icing impact on wind turbine production. Cold Regions Science and Technology 100: 36-49.

Li YG, Wang LY and Wang Z (2015) Modal analysis and three-dimensional modeling of $100 \mathrm{~kW}$ horizontal axis wind turbine blades. In: Proceedings of the 2015 international conference on applied science and engineering innovation. Jinan, China.

Mishnaevsky L, Branner K, Petersen H, et al. (2017) Materials for wind turbine blades: An overview. Materials 10(11): 1285.

Murray RE, Roadman J and Beach R (2019) Fusion joining of thermoplastic composite wind turbine blades: Lap-shear bond characterization. Renewable Energy 140: 501-512.

Ou Y, Chatzi EN, Dertimanis VK, et al. (2016) Vibration-based experimental damage detection of a small-scale wind turbine blade. Structural Health Monitoring: An International Journal 16(1): 79-96.

Rivkin D and Silk L (2012) Wind Turbine Operations, Maintenance, Diagnosis, and Repair (The Art and Science of Wind Power). Jones and Bartlett Publishers, Inc; 1st edn 5 July 2012.

Sellami T, Berriri H, Darcherif AM, et al. (2016) Modal and harmonic analysis of three-dimensional wind turbine models. Wind Engineering 40(6): 518-527.

Shah OR (2014) Identification and characterization of the mechanical and structural properties in static damage and fatigue resistance of a composite blade of a floating wind turbine. Thesis, University Of West Brittany, November.

Shokrieh MM \& Rafiee R (2020) Fatigue life prediction of wind turbine rotor blades. In: Fatigue Life Prediction of Composites and Composite Structures, pp. 681-710. Woodhead Publishing.

Shu L, Liang J, Hu Q, et al. (2017) Study on small wind turbine icing and its performance. Cold Regions Science and Technology 134: 11-19.

Sunden B and Wu Z (2015) On icing and icing mitigation of wind turbine blades in cold climate. Journal of Energy Resources Technology 137(5): 051203.

Supeni EE, Epaarachchi JA, Islam MM, et al. (2012) Design of smart structures for wind turbine blades. In: 2nd Malaysian postgraduate conference (MPC2012), Bond University, Gold Coast, Queensland, Australia, 7-9 July 2012. 
Tarfaoui M, Khadimallah H, Shah O, et al. (2013) Effect of spars cross-section design on dynamic behavior of composite wind turbine blade: Modal analysis. In: 4th international conference on power engineering, energy and electrical drives. Istanbul, Turkey.

Tarfaoui M, Nachtane M and Boudounit H (2020) Finite element analysis of composite offshore wind turbine blades under operating conditions. Journal of Thermal Science and Engineering Applications 12(1): 1-28.

Tarfaoui M, Nachtane M, Khadimallah H, et al. (2017) Simulation of mechanical behavior and damage of a large composite wind turbine blade under critical loads. Applied Composite Materials 25(2): 237-254.

Tarfaoui M, Pradillon JY and Shah OR (2015) Numerical investigation of a large composite wind turbine with different spar profiles using finite-element method. La Houille Blanche 5: 29-35.

Tarfaoui M and Shah OR (2013) Spar shape optimization of a multi megawatts composite wind turbine blade: modal analysis. In:Dr. Brahim Attaf(ed.) Chapter 6: Recent Advances in Composite Materials for Wind Turbine Blades . The World Academic Publishing Co. Ltd., pp.93-104.

Tartibu LK, Kilfoil M and Van Der Merwe AJ (2012) Vibration analysis of a variable length blade wind turbine. International Journal of Advances in Engineering \& Technology 4: 630-639.

Tenguria N, Mittal ND and Ahmed S (2011) Modal analysis for blade of horizontal axis wind turbine. Asian Journal of Scientific Research 4: 326-334.

Weijtjens W, Avendaño-Valencia LD, Devriendt C, et al. (2018) Cost-effective vibration based detection of wind turbine blade icing from sensors mounted on the tower. In: 9th European workshop on structural health monitoring (EWSHM 2018), Manchester, UK, 10-13 July 2018.

Zhiquan Y, Haomin M, Nengsheng B, et al. (2001) Structure dynamic analysis of a horizontal axis wind turbine system using a modal analysis method. Wind Engineering 25(4): 237-248. 